\title{
Clinical judgment and diagnostic reasoning of nursing students in clinical simulation
}

\author{
Julgamento clínico e raciocínio diagnóstico de estudantes de enfermagem em simulação clínica \\ Juicio clínico y razonamiento diagnóstico de estudiantes de enfermería en simulación clínica
}

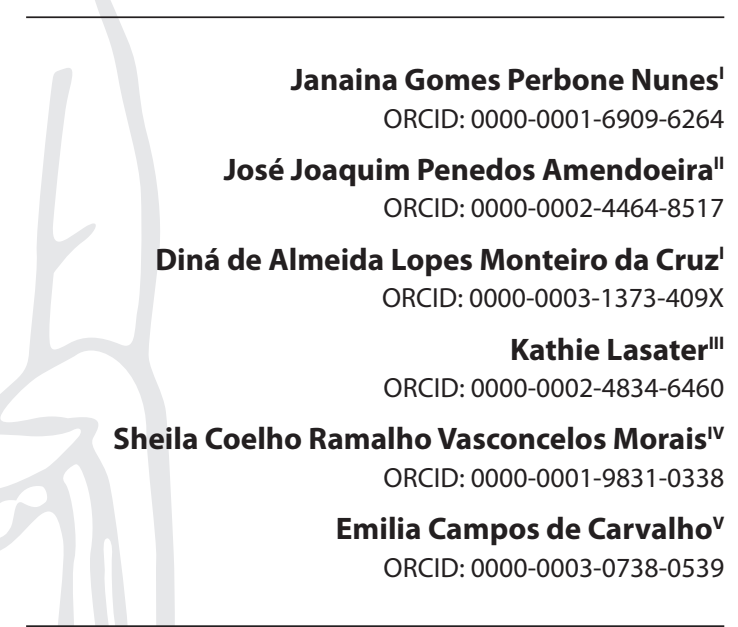

'Universidade de São Paulo. São Paulo, São Paulo, Brazil. "Instituto Politécnico de Santarém. Santarém, Portugal. "'Oregon Health \& Science University School of Nursing. Portland, United States of America. "Universidade Federal de Pernambuco. Recife, Pernambuco, Brazil. vUniversidade de São Paulo. Ribeirão Preto, São Paulo, Brazil.

How to cite this article: Nunes JGP, Amendoeira JJP, Cruz DALM, Lasater K, Morais SCRV, Carvalho EC. Clinical judgment and diagnostic reasoning of nursing students in clinical simulation. Rev Bras Enferm. 2020;73(6):e20180878. doi: http://dx.doi.org/10.1590/0034-7167-2018-0878

Corresponding author: Janaina Gomes Perbone Nunes E-mail: janaina.perbone@usp.br

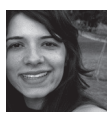

EDITOR IN CHIEF: Dulce Barbosa ASSOCIATE EDITOR: Antonio José de Almeida Filho

\section{ABSTRACT}

Objectives: to determine the degree of association between clinical judgment and diagnostic reasoning of nursing students in clinical simulation. Methods: this is a correlational research design using a quantitative approach. The sample consisted of 41 nursing students who assisted a patient with vaso-occlusive crisis in a high-fidelity clinical simulation setting. The instruments used included the Lasater Clinical Judgment Rubric - Brazilian Version and the Diagnostic Thinking Inventory. Results: clinical judgment was associated with diagnostic reasoning ( $r=0.313 ; p=0.046)$, as well as the "noticing" aspect of clinical judgment with diagnostic reasoning $(r=0.312 ; p=0.047)$. Conclusions: the results show that skills to interpret patient data are associated with diagnostic reasoning skills. Teaching clinical judgment skills is necessary to develop the diagnostic reasoning of nursing students.

Descriptors: Clinical Judgment; Clinical Reasoning; Patient Simulation; Clinical Simulation; Education, Nursing.

\section{RESUMO}

Objetivos: conhecer o grau de associação entre o julgamento clínico e o raciocínio diagnóstico de estudantes de enfermagem em simulação clínica. Métodos: estudo correlacional de abordagem quantitativa. A amostra foi composta por 41 estudantes de enfermagem, que realizaram atendimento a paciente em crise vaso-oclusiva, em cenário de simulação clínica de alta fidelidade. Os instrumentos utilizados compreenderam o Lasater Clinical Judgment Rubric - Brazilian Version e o Inventário de Raciocínio Diagnóstico. Resultados: o julgamento clínico apresentou associação com o raciocínio diagnóstico $(r=0,313 ; p=0,046)$, bem como o aspecto "reconhecimento do julgamento clínico" com o raciocínio diagnóstico $(r=0,312 ; p=0,047)$. Conclusões: os resultados evidenciam que as habilidades para interpretar os dados do paciente estão associadas às habilidades de raciocínio diagnóstico. O ensino das habilidades de julgamento clínico énecessário para o desenvolvimento do raciocínio diagnóstico dos estudantes de enfermagem.

Descritores: Julgamento Clínico; Raciocínio Clínico; Simulação de Paciente; Simulação Clínica; Educação em Enfermagem.

\section{RESUMEN}

Objetivos: conocer el grado de asociación entre el juicio clínico y el razonamiento diagnóstico de estudiantes de enfermería en simulación clínica. Métodos: estudio correlacional con enfoque cuantitativo. La muestra consistió en 41 estudiantes de enfermería, que atendieron a pacientes en una crisis vasooclusiva, en un escenario de simulación clínica de alta fidelidad. Los instrumentos utilizados incluyeron la rúbrica Lasater Clinical Judgment Rubric - Brazilian Version y el Inventario de Razonamiento Diagnóstico. Resultados: el juicio clínico se asoció con el razonamiento diagnóstico $(r=0.313 ; \mathrm{p}=0.046)$, así como el aspecto de "reconocimiento del juicio clínico" con el razonamiento diagnóstico $(r=0.312 ; p=0.047)$. Conclusiones: los resultados muestran que las habilidades para interpretar los datos del paciente están asociadas con las habilidades de razonamiento diagnóstico. La enseñanza de habilidades de juicio clínico es necesaria para el desarrollo del razonamiento diagnóstico de los estudiantes de enfermería. Descriptores: Juicio Clínico, Razonamiento Clínico; Simulación de Paciente; Simulación Clínica; Educación en Enfermería. 


\section{INTRODUCTION}

Nursing care has considerable impact on health outcomes of populations. Competence to provide nursing care requires clinical reasoning development, which comprises a complex cognitive process, including cognition, metacognition and knowledge of specific disciplines to collect and analyze patient data, interpret their meaning and consider possible actions ${ }^{(1)}$.

In nursing literature, the terms clinical reasoning, clinical judgment, diagnostic reasoning, critical thinking, and decision making are often used interchangeably and refer to thought processes. In this paper, the terms clinical judgment (CJ) and diagnostic reasoning (DR) were adopted as distinct phenomena. $\mathrm{CJ}$ refers to the thought process described by Tanner ${ }^{(2)}$ in the model of clinical judgment developed by nurses; and DR, according to Bordage, Grant and Marsden ${ }^{(3)}$, describes the thought process for identifying diagnoses.

In turn, clinical reasoning is the process by which information is obtained and interpreted so the necessary conclusions for health care can be reached ${ }^{(4)}$. Clinical decision making is the collection and interpretation of data performed by nurses, or other health professionals, to inform a choice of action mediated by limited information, interrelationships, emotional and ethical challenges, and time pressure ${ }^{(5)}$. Critical thinking comprises intentional, selfregulatory judgment, which results in interpretation, analysis, evaluation, inference, and clarification of evidence, concepts, criteria or contexts on which the judgment was based ${ }^{(6)}$.

Tanner's model of clinical judgment ${ }^{(2)}$ comprises four cyclicallyarticulated aspects: noticing, interpreting, responding, and reflecting,. 1)"Noticing" refers to perceiving or recognizing patient signs or symptoms, and it is rooted on nurses' expectations about patients' clinical conditions that, in turn, are influenced by their context, theoretical knowledge and previous experience. 2)"Interpreting" portrays the process by which nurses assign meaning to patient data identified through reasoning (analytical, narrative and/or intuitive). 3) "Responding" is the stage when an answer is offered to patients according to pertinent data. 4) "Reflecting" is the last stage, when nurses ponder patients' health outcomes in relation to provided action, and carry out professional performance assessment of all care processes, i.e., $\mathrm{CJ}$ is assessed ${ }^{(2)}$.

$\mathrm{DR}$, according to hypothesis generation theory, involves the organization of knowledge within memory and the strategies to access $\mathrm{it}^{(3,7-8)}$. Knowledge must be organized into patterns, networks that connect and facilitate information availability during analysis of a clinical cas $\mathrm{e}^{(3-7)}$. The strategies that contribute to access knowledge within memory (identification of relevant information) involve different thought processes during problem solving that characterize flexible thinking ${ }^{(3,8)}$. Therefore, DR can be more efficient through systematic storage of knowledge and clinical experience, in which key information is retrieved more easily when necessary $y^{(9-12)}$.

When considering Tanner's model of clinical judgment ${ }^{(2)}$ and Bordage, Grant and Marsden's model of diagnostic reasoning ${ }^{(3)}$, it is possible to see that CJ "noticing" and "interpreting" stages are associated with DR. While obtaining and interpreting clinical patient data, DR is guided by information that is organized into patterns, using mental strategies that facilitate access to such information. Therefore, this research aimed to observe such an association in nursing students who assisted a patient with pain in a high-fidelity clinical simulation setting. In addition to determining the degree of association between $\mathrm{CJ}$ and $\mathrm{DR}$, we also sought to compare CJ and DR of two groups of students with different curriculum levels, assuming that both processes are shaped throughout the professional training process.

Clinical simulation, a strategy to develop students' mental processes, is considered a student-centered teaching strategy that reproduces a real healthcare environment to replace and extend real experiences in guided-inquiry laboratory experiments ${ }^{(13)}$. To that end, the participants, immersed in a clinical simulation setting, carry out nursing actions as if they were in real environments, so that this simulated experience is more easily understood and handled when it occurs in clinical practice ${ }^{(13-14)}$. Clinical simulation is considered of high fidelity when it consists of equipment (mannequins), human resources, assertive clues, among other items ${ }^{(15)}$, which provide high emotional involvement, a necessary condition for students to have a meaningful learning experience ${ }^{(15-16)}$.

\section{OBJECTIVES}

To identify the degree of association between $\mathrm{CJ}$ and DR of nursing students in high-fidelity clinical simulation and compare $\mathrm{CJ}$ and DR of students of different curriculum levels.

\section{METHODS}

\section{Ethical aspects}

The Research Ethics Committee of Escola de Enfermagem de Ribeirão Preto at Universidade de São Paulo approved the project, under CAAE (Certificado de Apresentação para Apreciação Ética - Certificate of Presentation for Ethical Consideration) 24839113.2.0000.5393. The study followed the provisions of Resolution 466, December 12, $2012^{(17) .}$

\section{Study design, period and setting}

This is a descriptive, comparative and correlational research design conducted in 2014 at a school in the countryside of São Paulo.

\section{Population}

Students completing the penultimate and last term (seniors and juniors, respectively) of two undergraduate nursing courses participated in the research. Juniors who have attended and passed the class on care for hospitalized adults and elderly people, and seniors who have completed the class on urgent and emergency care were included in the study. Those classes propose the development of expected skills in clinical hospital care, close to the experience based on simulation in a high-fidelity clinical setting. Students who stopped participating in any stage of the research have been excluded.

Two hundred and sixty students were invited and forty-six students showed interest in participating in the study and signed the Informed Consent Form (ICF). Five students were excluded 
from the study; three because they stopped participating in one of the stages of the educational proposal, one of them because the practical activity was carried out only two months after its corresponding lecture, and the last one because he was demotivated about the activity and did not complete debriefing. Therefore, 41 students participated.

\section{Study variables}

The study variables were students'sex, age, previous experience with simulation, CJ, and DR. CJ was defined as a cyclical model that encompasses four aspects that articulate with each other ("noticing", "interpreting"," "responding", and "reflecting"). Therefore, the variable CJ was studied as well as the aforementioned four aspects, called subvariables. This variable and the subvariables were operationalized by the Lasater Clinical Judgment Rubric, an American instrument originally created by Lasater ${ }^{(18)}$, which was adapted for Brazilian culture and called Lasater Clinical Judgment Rubric - Brazilian Version (LCJR-BV) ${ }^{(19)}$. Intraclass correlation coefficient (ICC) for the LCJR-BV was 0.88; Cronbach's alpha of the global instrument was 0.889 ; for "noticing", $a=0.75$; for "interpreting", $a=0.64$; for "responding", $a=0.78$; and for "reflecting", $a=0.63^{(20)}$. The LCJR-BV presents 44 items, ranging from 1 to 4 points each, totaling a minimum score of 11 points and a maximum score of 44 .

DR was defined in two dimensions:"organization of knowledge within memory" and "flexible thinking". Organization of knowledge within memory comprises knowledge that is organized into patterns and networks that connect to each other and facilitate information availability during analysis of a clinical case. Flexible thinking is a strategy that contributes to access knowledge within memory, in addition to the possibility for nurses to use different mental processes in solving problems ${ }^{(3,8)}$. This variable and the subvariables were assessed using the Diagnostic Thinking Inventory (DTI) ${ }^{(21)}$. DTI was originally created by Bordage, Grant and Marsden ${ }^{(3)}$ and has been previously adapted to Brazilian culture by Rodrigues ${ }^{(21)}$. Pearson's correlation coefficient was 0.80 ; global instrument internal consistency by Cronbach's alpha was 0.80 ; organization of knowledge within memory was 0.742 ; and flexible thought was $0.635^{(21)}$. DTI has 41 items, with scores ranging from 1 to 6 points each item, so the minimum score is 41 and the maximum is 246 points.

Additionally, an instrument was used to guide collection and registration of students' sociodemographic variables (sex, age) and data on previous experience with simulation.

\section{Study protocol}

To evaluate the students' DR and CJ, a high-fidelity clinical simulation setting to assist a patient with sickle cell anemia in vaso-occlusive crisis was developed, based on the NLN/Jeffries Simulation Theory guidelines ${ }^{(22-23)}$. The simulation, including debriefing of all participants, was recorded on video.

The students were evaluated in relation to obtaining data (interview, physical examination, and laboratory data), data interpretation, implemented nursing interventions, and evaluation of intervention effects. Assessment of each participant lasted approximately 15 minutes. Then, an interval of 10 minutes was established for students to settle their emotions and for the research team to reorganize the environment for debriefing.

Debriefing, lasting approximately 20 minutes, comprised the student's reflection on his or her patient care performance during the clinical simulation setting. To do so, the facilitator, based on the Gibbs model(24), asked questions to encourage students to identify their strengths, weaknesses, contents and skills that were mobilized in that setting, and to reflect on what was still necessary to be explored and experienced, regarding their training. The following questions were asked: How did you feel about providing care for this patient? What positive actions did you take? What would you do differently if you had another opportunity to see that same patient? What do you take from this experience to your future clinical practice?

After debriefing, students responded, individually, to the instrument on sociodemographic data and to the DTI. The videos with records of the simulation-based experience and the debriefing were analyzed by three independent observers who assessed the students' performance using LCJR-BV.

\section{Data analysis}

For the results of performance observation in $\mathrm{CJ}$ and $\mathrm{DR}$, calculations included frequency, interval, median, mean and standard deviation. The Shapiro-Wilk test was used to verify whether the numerical variables followed a normal distribution. Variables that showed normal distribution were flexible thinking $(p=0.552), D R$ (total score) $(p=0.543)$, and CJ (total score) $(p=0.413)$. Calculation of the difference between the performances of junior and senior students in variables with normal distribution was made with Student's $t$ test, followed by application of the Levene test to verify equality of variances. To calculate the difference between students in variables that did not show normal distribution, the U Mann-Whitney test was applied. To verify the degree of association between DR and CJ of participants through the results of DTI and LCJR-BV scores, the Spearman coefficient was calculated, since the variables had a low frequency of subjects and most did not follow normal distribution.

In this study, the classifications for correlation measures established by the British Medical Journal (BMJ) ${ }^{(25)}$ were adopted. The $r$ value between 0.00 and 0.19 is interpreted as no association or very weak association; a value of 0.20 to 0.39 is interpreted as a weak association; 0.40 to 0.59 is interpreted as moderate; a value from 0.60 to 0.79 is interpreted as strong; and a value from 0.8 to 1.0 is interpreted as very strong.

\section{RESULTS}

Data from 41 participants were analyzed, out of whom 23 belonged to the junior group and 18 to the senior group. Most participants were female 37 (90.2\%) and reported having previous experience in clinical simulation settings (all senior participants reported having such experience). The participants were between 20 and 46 years old, with a mean value of 23.9 years $(S D=4.4)$, considering that there were older participants in the senior students' group. 
In relation to the performance of students for DR, in the sample, the average score was 171 points, a level considered broad skill(26). The apparent difference in total average scores obtained by senior students, slightly higher than that of juniors, was not supported by the statistical test $(p=0.334)$. Concerning flexible thinking, the results of junior students and senior students showed no difference $(p=0.125)$ and regarding organization of knowledge within memory, the average values were similar $(p=0.762)$ (Table 2$)$.

Table 1 - Comparison of performance in clinical judgment between junior and senior nursing students, Ribeirão Preto, São Paulo, Brazil, 2014

\begin{tabular}{|c|c|c|c|c|c|c|}
\hline Aspects & $\mathbf{n}$ & Mean & SD & Median & Interval & Value $p$ \\
\hline \multicolumn{7}{|l|}{ Noticing } \\
\hline Junior & 23 & 6.7 & 1.8 & 7 & $3-10$ & $0.149 *$ \\
\hline Senior & 18 & 7.6 & 1.5 & 7.5 & $5-10$ & \\
\hline \multicolumn{7}{|c|}{ Interpreting } \\
\hline Junior & 23 & 5.0 & 1.1 & 5 & $3-6$ & $0.021 *$ \\
\hline Senior & 18 & 5.8 & 0.9 & 6 & $4-8$ & \\
\hline \multicolumn{7}{|c|}{ Responding } \\
\hline Junior & 23 & 10.0 & 2.2 & 10 & $7-14$ & $0.183^{*}$ \\
\hline Senior & 18 & 11.0 & 2.2 & 12 & $8-14$ & \\
\hline \multicolumn{7}{|l|}{ Reflecting } \\
\hline Junior & 23 & 5.6 & 0.8 & 6 & $3-6$ & $0.159^{*}$ \\
\hline Senior & 18 & 5.8 & 0.9 & 6 & $4-7$ & \\
\hline \multicolumn{7}{|l|}{ Total score } \\
\hline Junior & 23 & 28.8 & 4.9 & 30 & $21-36$ & $0.110^{* *}$ \\
\hline Senior & 18 & 31.2 & 4.1 & 30 & $25-39$ & \\
\hline
\end{tabular}

Table 2 - Comparison of performance in diagnostic reasoning among junior and senior nursing students, Ribeirão Preto, São Paulo, Brazil, 2014

\begin{tabular}{|c|c|c|c|c|c|c|}
\hline Variables & $\mathbf{n}$ & Mean & Median & Interval & SD & Value $p$ \\
\hline \multicolumn{7}{|c|}{ Flexible thinking } \\
\hline Junior & 23 & 86.6 & 87 & $61-106$ & 12.7 & $0.125^{*}$ \\
\hline Senior & 18 & 92.5 & 92.5 & $71-121$ & 11.1 & \\
\hline \multicolumn{7}{|c|}{$\begin{array}{l}\text { Organization of knowledge } \\
\text { within memory }\end{array}$} \\
\hline Junior & 23 & 82.0 & 83 & $68-92$ & 6.3 & $0.762^{* *}$ \\
\hline Senior & 18 & 81.6 & 83 & $50-98$ & 11.6 & \\
\hline \multicolumn{7}{|l|}{ Total score } \\
\hline Junior & 23 & 168.6 & 170 & $132-195$ & 16.9 & $0.334^{*}$ \\
\hline Senior & 18 & 174.1 & 176 & $143-216$ & 19.3 & \\
\hline
\end{tabular}

Table 3 - Spearman's correlation coefficient $(r)$ and p-value between clinical judgment performance and nursing students' diagnostic reasoning skills ( $n=41$ ), Ribeirão Preto, São Paulo, Brazil, 2014

\begin{tabular}{lcccc}
\hline $\begin{array}{l}\text { Clinical } \\
\text { Judgment }\end{array}$ & & \multicolumn{4}{c}{ Diagnostic Reasoning } & \\
& & $\begin{array}{c}\text { Flexible } \\
\text { thinking }\end{array}$ & $\begin{array}{c}\text { Organization } \\
\text { of knowledge } \\
\text { within memory }\end{array}$ & $\begin{array}{c}\text { Total } \\
\text { score }\end{array}$ \\
\hline Noticing & $r$ & 0.288 & 0.227 & 0.312 \\
Interpreting & $p$ value & 0.067 & 0.154 & 0.047 \\
Responding & $r$ & 0.216 & 0.164 & 0.233 \\
Reflecting & $p$ value & 0.174 & 0.305 & 0.142 \\
Total score & $r$ & 0.196 & 0.267 & 0.233 \\
& $p$ value & 0.220 & 0.092 & 0.143 \\
& $r$ & 0.029 & -0.099 & -0.041 \\
& $p$ value & 0.856 & 0.538 & 0.800 \\
& $r$ & 0.278 & 0.289 & 0.313 \\
\hline
\end{tabular}

Table 4 - Spearman's correlation coefficient $(r)$ and p-value between performance in clinical judgment and diagnostic reasoning of junior nursing students ( $n=23)$, Ribeirão Preto, São Paulo, Brazil, 2014

\begin{tabular}{|c|c|c|c|c|}
\hline \multirow[b]{2}{*}{$\begin{array}{l}\text { Clinical } \\
\text { Judgment }\end{array}$} & & \multicolumn{3}{|c|}{ Diagnostic Reasoning } \\
\hline & & $\begin{array}{l}\text { Flexible } \\
\text { thinking }\end{array}$ & $\begin{array}{c}\text { Organization } \\
\text { of knowledge } \\
\text { within memory }\end{array}$ & $\begin{array}{l}\text { Total } \\
\text { score }\end{array}$ \\
\hline Noticing & $\begin{array}{c}r \\
p \text { value }\end{array}$ & $\begin{array}{l}0.394 \\
0.060\end{array}$ & $\begin{array}{l}0.310 \\
0.151\end{array}$ & $\begin{array}{l}0.436 \\
0.037\end{array}$ \\
\hline Interpreting & $\begin{array}{c}r \\
p \text { value }\end{array}$ & $\begin{array}{l}0.152 \\
0.488\end{array}$ & $\begin{array}{l}-0.015 \\
0.947\end{array}$ & $\begin{array}{l}0.091 \\
0.678\end{array}$ \\
\hline Responding & $\begin{array}{c}r \\
p \text { value }\end{array}$ & $\begin{array}{l}0.070 \\
0.751\end{array}$ & $\begin{array}{l}0.106 \\
0.629\end{array}$ & $\begin{array}{l}0.064 \\
0.771\end{array}$ \\
\hline Reflecting & $\begin{array}{c}r \\
p \text { value }\end{array}$ & $\begin{array}{l}-0.047 \\
0.832\end{array}$ & $\begin{array}{l}-0.115 \\
0.600\end{array}$ & $\begin{array}{r}-0.131 \\
0.551\end{array}$ \\
\hline Total score & $\begin{array}{c}r \\
p \text { value }\end{array}$ & $\begin{array}{l}0.196 \\
0.370\end{array}$ & $\begin{array}{l}0.145 \\
0.509\end{array}$ & $\begin{array}{l}0.186 \\
0.396\end{array}$ \\
\hline
\end{tabular}

Table 5 - Spearman's correlation coefficient $(r)$ and p-value between clinical judgment performance and diagnostic reasoning of senior nursing students ( $n=18)$, Ribeirão Preto, São Paulo, Brazil, 2014

\begin{tabular}{lcccc}
\hline $\begin{array}{l}\text { Clinical } \\
\text { Judgment }\end{array}$ & & \multicolumn{3}{c}{ Diagnostic Reasoning } \\
& & $\begin{array}{c}\text { Flexible } \\
\text { thinking } \\
\text { Organization } \\
\text { of knowledge } \\
\text { within memory }\end{array}$ & $\begin{array}{l}\text { Total } \\
\text { score }\end{array}$ \\
\hline Noticing & $r$ & 0.002 & 0.151 & 0.084 \\
Interpreting & $p$ value & 0.995 & 0.551 & 0.740 \\
& $r$ & 0.194 & 0.378 & 0.309 \\
Responding & $p$ value & 0.441 & 0.122 & 0.213 \\
Reflecting & $r$ & 0.304 & 0.439 & 0.382 \\
& $p$ value & 0.220 & 0.069 & 0.118 \\
Total score & $r$ & 0.046 & -0.072 & 0.002 \\
& $p$ value & 0.857 & 0.777 & 0.994 \\
& $r$ & 0.455 & 0.433 & 0.502 \\
& $p$ value & 0.058 & 0.073 & 0.034 \\
\hline
\end{tabular}

In this study, age did not affect the performance in CJ or the ability for DR of nursing students (Spearman's correlation coefficients, $r=0.125 p=0.435 ; r=0.151 p=0.346$, respectively). There was also no difference in performance in $C J$ and in $D R$, relative to previous experience with clinical simulation (U Mann-Whitney test, $p=0.97$ and $p=0.603$, respectively). Due to the small number of male subjects, it was not possible to test the association of the sex variable with DR and CJ.

The data showed, for the total sample of nursing students $(n=41)$, that $C J$ was associated with DR $(r=0.313 ; p=0.046)$. When analyzing the aspects and dimensions of these thought processes, CJ"noticing" was associated with DR (total score) $(r=0.312$; $\mathrm{p}=0.047$ ) (Table 3).

When analyzing the associations of $\mathrm{CJ}$ and $\mathrm{DR}$ in the two groups of students, separately, the results were different (Tables 4 and 5).

\section{DISCUSSION}

The data from this study show that senior students reached a higher average score only in "interpreting", when compared to junior students. This finding may be related to the students' curriculum development time. Greater acquisition of theoretical knowledge and clinical experiences stored within memory may 
have contributed to the ability to select relevant data from a clinical case, relate them to each other and prioritize interventions ${ }^{(27-28)}$.

Chinese nursing students of the second and third terms $(n=113)$ participated in a study in which they performed four high-fidelity clinical simulation sessions in caring for patients with appendicitis; elderly patients with chronic obstructive pulmonary disease; elderly patients with gastrointestinal bleeding; and elderly patients with acute myocardial infarction, presenting the following average scores in CJ aspects:"noticing", 7.36, "interpreting", 5.09, "responding", 8.69, and "reflecting", 4.75(29). Although the present study presents similar results to the aforementioned one ${ }^{(29)}$, except for "responding" (highest values: 10 points for junior students and 11 points for senior students), the studies are not comparable. There was a difference in the number of sessions and in the content of simulation settings to which the students were submitted, besides possible curricular differences of each institution and country.

In the present study, the association between DR and CJ was confirmed, both for the total sample $(n=41)$ and for senior students $(n=18)$. The more advanced a student's curriculum level, the better they performed $\mathrm{CJ}$ in association to the ability to identify diagnoses.

A study with 160 students in the last term of nursing school, which examined the impact of critical thinking on $C J$ in a pediatric drug administration setting, showed that LCJR results confirm that 11 critical thinking variables represented $17 \%$ of the LCJR scores. It also showed that skills of deduction and analysis of critical thinking, measured by the instrument Health Science Reasoning Test, are predictors of $\mathrm{CJ}^{(30)}$. These results support the idea that deduction and analysis skills are common in both processes.

CJ "noticing" was associated with DR (total) among the set of junior students ( $n=23$ ) (Table 2). It is possible evidence that data collection about the patient (interview and physical examination) leads to the identification of nursing diagnoses.

CJ (total) was associated with DR (total) among senior students (Table 3). It is possible that senior students showed homogeneous development in all aspects of CJ and dimensions of DR. Still, both thought processes (CJ and DR) possibly have similarities in their development within teaching.

The association between the "noticing" aspect of CJ and DR was evidenced in the total set and among junior students. This may indicate, as described in relevant literature, that knowledge organized into categories and the existence of strategies to access knowledge contained within memory are important factors for the expectations of nurses about the clinical condition of patients during data collection in nursing care $\mathrm{e}^{(2-3,17)}$. Thus, it is suggested that the reasoning pattern involved in CJ "noticing" is related to the DR adopted in this research.
Since DR utilizes organization of knowledge within memory and strategies to access key information in thoughts ${ }^{(3,7)}, \mathrm{CJ}$ parallelism is therefore considered to be present in "noticing" as well as in "interpreting". However, although these skills in organizing and prioritizing data seem to be present in DR, there was no association between DR and the interpretation aspect of $C J$.

Sociodemographic data showed no association in performance for CJ and DR. However, in an American study, sex and ethnicity were considered statistically significant predictors for $\mathrm{CJ}^{(30)}$.

High-fidelity clinical simulation was important as a teaching strategy for CJ and DR manifestation, as it provided students with a safe context to exercise and improve clinical skills from an interview to evaluation of nursing results. The use of Lasater Clinical Judgment Rubric - Brazilian Version ${ }^{(17-18)}$ contributed to the development of this study on different aspects of nursing students' $C J$, with results that are add to the evidence already available in literature for reflection in a teaching context.

\section{Study limitations}

The sample size may have intervened in the obtained results, since it may be considered too small to make inferences and generalizations. Out of 260 students, only 46 accepted to participate in the study.

\section{Contributions to nursing}

Understanding these two thought processes involved in the professional clinical development of nursing students provides support for nursing education improvement.

\section{CONCLUSIONS}

The associations identified by the results of the study highlight possible overlaps between CJ and DR. The initial approach to seeking $C J$ information coincides with that of DR. Deepening nursing students' knowledge about the reasoning involved in data collection during contact with patients is paramount. Interpreting $\mathrm{CJ}$ among senior students was more developed in relation to junior students, thus, this result allows us to conclude that curriculum advancement is followed by skill development to assign meaning to clinical data.

\section{FUNDING}

This study was financed in part by Coordenação de Aperfeiçoamento de Pessoal de Nível Superior - Brazil (CAPES) - Finance Code 001 and by Conselho Nacional de Desenvolvimento Científico e Tecnológico (CNPq) - Brazil - Process 305531 / 2013-1.

\section{REFERENCES}

1. Simmons B. Clinical reasoning: concept analysis. J Adv Nurs. 2010;66(5):1151-8. doi: 10.1111/j.1365-2648.2010.05262.x

2. Tanner CA. Thinking like a nurse: a research based model of clinical judgment in nursing. J Nurs Educ. 2006;45(6):204-11. Available from: https:// www.ccdhb.org.nz/working-with-us/nursing-and-midwifery-workforce-development/preceptorship-and-supervision/3-tanner-2006.pdf

3. Bordage G, Grant J, Marsden P. Quantitative assessment of diagnostic ability. Med Educ. 1990;24(5):413-25. doi: 10.1111/j.1365-2923.1990. tb02650.x 
4. Menezes SSC, Corrêa CG, Silva RCG, Cruz DALM. Clinical reasoning in undergraduate nursing education: a scoping review. Rev Esc Enferm USP. 2015;49(6):1037-44. doi: 10.1590/S0080-623420150000600021

5. Anderson NE, Slark J, Gott M. Unlocking intuition and expertise: using interpretative phenomenological analysis to explore clinical decision making. J Res Nurs [Internet]. 2019[cited 2019 Aug 13];24(1-2):88-101. Available from: https://journals.sagepub.com/doi/ full/10.1177/1744987118809528

6. American Philosophical Association. Critical thinking: a statement of expert consensus for purposes of educational assessment and instruction. Millbrae: California Academic Press; 1990.

7. Bordage G, Zacks R. The structure of medical knowledge in the memories of medical students and general practitioners: categories and prototypes. Med Educ. 1984;18(6):406-16. doi: 10.1111/j.1365-2923.1984.tb01295.x

8. Cholowski KM, Chan LKS. Knowledge-driven problem-solving models in nursing education. J Nurs Educ [Internet]. 1995[cited 2015 Aug 13];34(4):148-54. Available from: http://europepmc.org/article/med/7782881

9. Benner P. From Novice to expert: excellence and power in clinical nursing practice [Internet]. Menlo Park: Addison-Wesley, 1984[cited 2015 Aug 13]. Available from: https://opp47lwij01.storage.googleapis.com/MDIwMTAwMjk5WA==01.pdf

10. Bowen JL. Educational strategies to promote clinical diagnostic reasoning. N Engl J Med. 2006;355(21):2217-25. doi: 10.1056/ NEJMra054782

11. Schmidt H, Norman G, Boshuizen H. A cognitive perspective on medical expertise: theory and implications. Acad Med [Internet]. 1990[cited 2015 Aug 13];65(10):611-21. Available from: https://repub.eur.nl/pub/2722

12. Tanner C. Toward development of diagnostic reasoning skills. In Carnevali D, Mitchell P, Woods N, Tanner C, (Eds.). Diagnostic Reasoning in Nursing. Philadelphia: J. B. Lippincott; 1984.

13. Gaba DM. The future of simulation in health care. BMJ Qual Saf. 2004(Suppl 1):2-10. doi: 10.1136/qshc.2004.009878

14. Morton PG. Creating a laboratory that simulates the critical care environment. Crit Care Nurse. 1996;16(6):76-81. doi: 10.4037/ ccn1996.16.6.76

15. Inacsl Standards Committee. INACSL standards of best practice: SimulationSM Simulation design. Clin Simul Nurs. 2016;12(S):5-12. doi: 10.1016/j.ecns.2016.09.005

16. Kolb AY, Kolb DA. The learning way meta-cognitive aspects of experiential learning. Simul Gaming. 2009;40(3):297-327. doi: $10.1177 / 1046878108325713$

17. Ministério da Saúde (BR) Conselho Nacional da Saúde. Resolução n 466, 12 de dezembro de 2012. Diário Oficial da União, Brasília, Junho 13. 2013, Seção 1, p. 59.

18. Lasater K. Clinical judgment development: using simulation to create an assessment rubric. J Nurs Educ. 2007;46(11):496-503. doi: 10.3928/01484834-20071101-04

19. Nunes JGP, Lasater K, Oliveira-Kumakura ARS, Garbuio DCB, Braga FTMM, Carvalho EC. Adaptation of the Lasater Clinical Judgment Rubric to the Brazilian culture. Rev Enferm UFPE. 2016;10 (Suppl. 6):4828-36. doi: 10.5205/1981-8963-v10i6a11262p4828-4836-2016

20. Morais SC, Nunes JG, Lasater K, Barros AL, Carvalho EC. Confiabilidade e validade da Lasater Clinical Judgment Rubric: Brazilian Version. Acta Paul Enferm. 2018;31(3):265-71. doi: 10.1590/1982-0194201800038

21. Rodrigues AS. Baccalaureate nurses and undergraduate students' diagnostic reasoning [Tese] [Internet]. Sao Paulo: Universidade de São Paulo; 2012[cited 2015 Aug 13]. Available from: http://www.teses.usp.br/teses/disponiveis/7/7139/tde-14112012-103847/.../Tese_final.pdf

22. Jeffries PR, Rogers B, Adamson K. NLN Jeffries simulation theory: brief narrative description. Nurs Educ Perspect. 2015;35(5):292-3. doi: $10.5480 / 1536-5026-36.5 .292$

23. Jeffries PR, Rogers KJ. Theoretical framework for simulation design. In Jeffries PR, Rogers, KJ, (Eds.). Simulation in Nursing education: from conceptualization to evaluation. 2nd ed. New York: National League for Nursing, 2012:25-41. Available from: https://tmj4h3rgm06.storage. googleapis.com/MDk3Nzk1NTc0NQ==06.pdf

24. Gibbs, G. Learning by Doing: a guide to teaching and learning methods. London: Fell, 1988.

25. Swinscow TDV (revised by Campbell MJ). Statistics at Square One: Correlation and Regression [Internet]. Campbell: BMJ Publishing Group, 1997[cited 2015 Aug 13]. Available from: http://www.bmj. com/collections/statsbk/11.dtl

26. Sobral DT. Characteristics of the Bordage, Grant \& Marsden Diagnostic Thinking Inventory. Psicol Teor Pesq 2001;17(1):79-85. doi: 10.1590/ S0102-37722001000100011

27. Lasater K. Clinical judgment: the last frontier for evaluation. Nurse Educ Pract. 2011;11(2):86-92. doi: 10.1016/j.nepr.2010.11.013

28. Nielsen A, Stragnell S, Jester P. Guide for reflection using the clinical judgment model. J Nurs Educ. 2007;46(11):513-6. doi: 10.3928/01484834-20071101-06

29. Yuan HB, Williams BA, Chan YM. Nursing students' clinical judgment in high-fidelity simulation based learning: a quasi-experimental study. J Nurs Educ Pract. 2014;4(5):7-15. doi: 10.5430/jnep.v4n5p7

30. Cazzell MA, Anderson M. The impact of critical thinking on clinical judgment during simulation with senior nursing students. Nurs Educ Perspect [Internet]. 2016[cited 2019 Aug 13];37(2):83-90. Available from: https://pubmed.ncbi.nlm.nih.gov/27209866/ 